\title{
Learning across disciplines in socio-environmental problem framing
}

\author{
Deana Pennington ${ }^{1 *}$, Shirley Vincent ${ }^{2}$, Dave Gosselin ${ }^{3}$, Kate Thompson ${ }^{4}$ \\ ${ }^{1}$ University of Texas at El Paso, Texas, USA \\ ${ }^{2}$ Vincent Evaluation Consulting, LLC, Oklahoma, USA \\ ${ }^{3}$ University of Nebraska-Lincoln, Nebraska, USA \\ ${ }^{4}$ Queensland University of Technology, Brisbane, Australia
}

\begin{abstract}
Modelling complex socio-environmental problems requires integration of knowledge across disparate fields of expertise. A key challenge is understanding how social learning across disciplines occurs in scientific research teams, in order that integrated knowledge is co-created. This article introduces a new framework for training researchers to integrate their knowledge across disciplines, based on current understanding of how inter- and transdisciplinary learning in research teams occurs. The framework was generated from a synthesis of learning, cognitive, and social science theories, and combines facilitated, structured negotiation processes with co-creation of boundary objects. It was used in two, 9 to 10-day intensive training workshops for doctoral students. This article describes the framework, workshop design, analysis of data collected during the workshops related to knowledge integration processes, what has been learned from the results, and the impact on participants. All participants indicated the experience was transformative, provided knowledge and skills unavailable elsewhere, filled gaps in their graduate education programs, and improving confidence in their capacity for inter- and transdisciplinary research. Pre- and post-workshop surveys confirm that the framework changed participants' knowledge, behaviors, and competencies for engaging across disciplines. Many students have reported they have used the framework in a variety of other research and education settings, indicating they are able to transfer their new competencies to other contexts. Findings contribute to understanding of how to more effectively train researchers to integrate knowledge across disciplines for complex societal problem solving.
\end{abstract}

\section{Keywords}

Interdisciplinary; knowledge integration; model-based reasoning; boundary objects; complex problem solving

\section{Introduction}

Socio-environmental systems (SES) research teams typically leverage highly diverse expert knowledge, often including researchers from biophysical and social sciences, engineers, and modelers as well as experts from outside the research community (Cairns et al., 2020; Klein, 2020; Norström et al., 2020). It can be extremely challenging to understand and integrate team member's expertise because of the lack of background knowledge in each other's fields, unfamiliar disciplinary jargon, and very different methods (Eigenbrode et al., 2007; O'Rourke et al., 2013, 2016; Tkachenko, 2017). This article focuses on developing a better understanding of social learning across disciplines to more effectively integrate knowledge.

\section{Correspondence: \\ Contact D. Pennington at ddpennington@utep.edu}

Cite this article as:

Pennington, D., Vincent, S., Gosselin, D., \& Thompson, K.

Learning across disciplines in socio-environmental problem framing

Socio-Environmental Systems Modelling, vol. 3, 17895, 2021, doi:10.18174/sesmo.2021a17895

This work is licensed under a Creative Commons Attribution-NonCommercial 4.0 International License. 
Social learning has been recognized as important throughout the life of an SES project (de Kraker et al., 2011; Ernst, 2019; Fernández-Giménez et al., 2019; Johnson et al., 2012; Schneider \& Rist, 2014; Scholz et al., 2014; Voinov \& Bousquet, 2010). However, few studies address social learning during the earliest phase of an SES research team, the problem framing phase. The modelling community has described problem framing as including: defining the purpose of the research, deciding the disciplines to be involved, bridging epistemologies across disciplines, synchronizing mental models, deciding on scales of interest, conceptualizing the system, and identifying sources of uncertainty (Argent et al., 2016; Badham et al., 2019; Elsawah et al., 2020; Hamilton et al., 2015; Jakeman et al., 2006; Koch et al., 2019; Villamor et al., 2020; Voinov et al., 2016; Voinov \& Bousquet, 2010). This requires time to iterate over many possible problem framings and converge on a shared, integrated conceptualization (Jakeman et al., 2006).

Studies of inter- and transdisciplinary (ITD) research teams indicate that team members struggle to combine knowledge (Cairns et al., 2020; Killion et al., 2018; National Academy of Sciences, 2004; National Research Council, 2015; Pennington, 2008; Roy et al., 2013; Stokols et al., 2008; Xue et al., 2018, 2020). A primary goal early in the life of an SES research team must be to confront the extreme cognitive distance between team members so that social learning is enhanced (Cairns et al., 2020; Fiore et al., 2010; Fiore \& Schooler, 2004; Fiore \& Wiltshire, 2016; Hall et al., 2018; Pennington et al., 2016).

This article describes a new framework for facilitating social learning and integrative problem framing, referred to as the EMBeRS framework (Employing Model Based Reasoning for Socio-Environmental Synthesis). This framework, initially conceptualized in Pennington (2016) and Pennington et al. (2016), synthesizes theories from learning, cognitive, and social sciences to develop a process supporting social learning. The EMBeRS framework was pilot tested in two intensive training workshops involving doctoral students from across the U.S. This article presents the EMBeRS framework and its theoretical foundations; describes the workshops and their design using the EMBeRS framework and documents the impact of the doctoral workshops on participants. The framework is generic and can be used in any SES team.

\section{Background}

Three learning and cognition theories are central to the design of the EMBeRS framework: transformative learning (Mezirow, 1981, 1997, 2018), experiential learning (Kolb, 2005; Kolb, 1984), and model-based reasoning (Nersessian, 1999, 2006). One theory from social science is also critical: boundary crossing (Star \& Griesemer, 1989). Although many relevant learning and social science theories could be discussed, these are included because they provide terminology that is used throughout the remainder of the article.

Transformative learning theory was developed to explain the process through which adult perspectives may be profoundly changed, becoming more inclusive, discriminating, permeable, and integrative. This theory highlights two key processes that lead to radical perspective changes: critical reflection and reflective discourse. Critical reflection is the process by which one interprets and makes sense of experiences. Reflective discourse involves dialogue devoted to assessing competing interpretations by critically examining evidence, arguments, and alternative points of view. Transformative learning is postulated to be commonly precipitated by a "disorienting dilemma" that invokes reflection and reflective discourse. Mezirow (1997) suggests transformative learning can be facilitated by helping learners become aware and critical of their own and others' assumptions; practice recognizing different frames of reference and redefining problems from different perspectives; and assistance in participating effectively in discourse that is learner-centered, participatory, interactive, and involves group deliberation.

When ITD researchers initially engage they need to collaboratively formulate a precise problem to tackle. However, they experience disorientation in engaging with each other-with different disciplines, perspectives, epistemologies, methodologies, and assumptions about working together (Godemann, 2008; Pennington et al., 2013). The disorientation results from a deluge of new concepts and vocabulary that do not fit their existing mental models; new collaborators they may not know very well and who may have very different goals, values, and behavioral characteristics (Gosselin et al., 2020; O'Rourke et al., 2013); unfamiliar data and methods (Pennington et al., 2020); and new tools that may have steep learning curves. Yet these disorienting features of ITD research provide an opportunity for creative thinking (Bransford et al., 2006). Transformative learning theory provides the team with mechanisms to address the disorientation (Figure 1). The disorienting dilemma must 
invoke a process of reflection by each collaborator on how these concepts, data, methods, and technologies fit together. As each collaborator struggles independently with the same challenges, they must also collectively engage in reflective discourse that progressively (re)frames the problem, enabling negotiation of a shared conceptual model of the problem (Fiore et al. 2004; Pennington et al., 2013; Pennington et al., 2016). Hence, transformative learning, and its theoretical explanation for how disorienting dilemmas lead to the radical perspective changes necessary for successfully integrating different perspectives, is at the heart of ITD problem framing. However, because researchers do not understand each other, reflection and reflective discourse are insufficient to overcome the challenges.

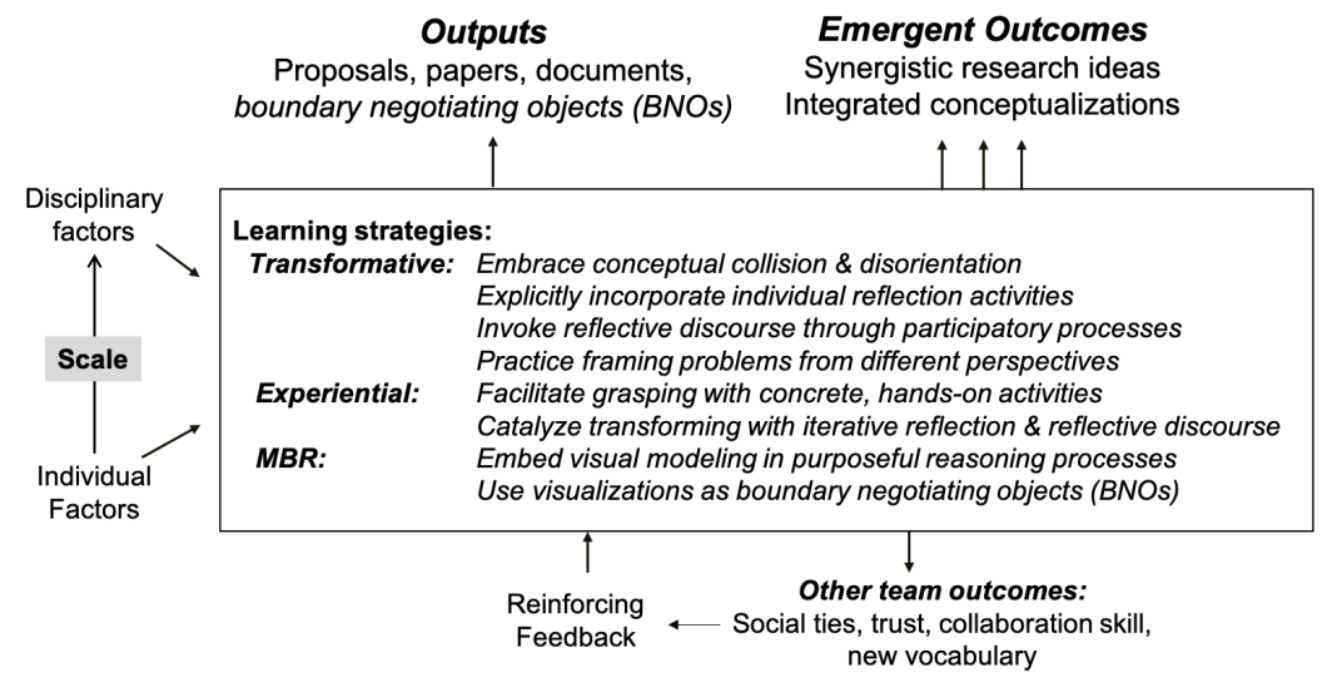

Figure 1: Learning strategies for overcoming individual and disciplinary obstacles to formulating synergistic, integrated research as emergent outcomes of teamwork. Modified from Pennington (2011).

Experiential learning focuses on cognitive grasping and transforming processes that take place during experiences that invoke reflection. Grasping processes enable the learner to perceive and apprehend information. Transforming processes act on the information that has been grasped, connecting it with what is already known. Experiential learning theory suggests that ITD activities must provide more effective grasping and transforming experiences. Many research teams adopt one of two strategies (Borrego et al., 2014): 1) multidisciplinary seminars; or 2) ad hoc dialogue. While these can be useful in some contexts, both strategies are ineffective because people from distant disciplines do not have the background to understand what is being said unless proactive actions are taken to provide basic aids in advance, such as plain English summaries, glossaries, or overview articles of the subject (Anthony et al., 2007; Zajac et al., 2013). Experiential learning suggests processes are needed that facilitate grasping through hands-on activities and transforming through reflective activities.

Model-based reasoning (MBR) posits that in complex problem-solving tasks, humans reason by iteratively constructing internal mental models of the situation, and that external representations of mental models support generation of new mental models, i.e. invoking conceptual change (Nersessian, 1999). MBR includes the use of analogies, metaphor, visual models, and/or diagrams for abstraction and representation of complex concepts. Research in cognitive science suggests that externalization of mental models enables the offloading and summarizing of complex information so that learners can grasp and transform more information (Larkin \& Simon, 1987).

Analogous findings in social science studies of group work have recognized that externalized representations, referred to in that literature as "boundary objects", facilitate the exchange of information across the boundaries of different expertise (Star and Griesemer 1990). Boundary objects are objects which represent individual needs while providing common connections. Lee (2007) identified that certain kinds of boundary objects facilitate negotiation across perspectives, and referred to these as "boundary negotiating objects". Visual externalizations of mental models will henceforth be referred to as boundary negotiating objects (BNOs), to avoid confusion due to overuse of the word model. 
MBR theory suggests that grasping and transforming experiences can be enabled through the purposeful use of BNOs, but it emphasizes that these must be embedded in an effective reasoning process. Co-creating BNOs, alone, will not necessarily lead to integrated knowledge, since BNOs can easily represent multiple forms of knowledge without integrating them. However, there is little known about how to design an effective learning process around co-creation of BNOs. The EMBeRS framework attempts to fill this gap.

\subsection{The EMBeRS Framework}

The EMBeRS framework formalizes the above basic understandings to describe the process of learning, reasoning, and negotiating a shared framing of the problem across perspectives using BNOs (Figure 2). The emphasis of the EMBeRS framework is on the process rather than the specific BNO that is used. Any BNO could be effective if the process is effective.

The EMBeRS framework was initially comprised of two distinct process models: 1) a systems model representing the flow of information between individuals within groups mediated by BNOs (Pennington 2016); and 2) a model focused on the evolution of BNOs during group interactions (Pennington et al., 2016). The systems model primarily focused on cognitive processes and skills, with explicit recognition that other types of skills mediate the outcome of cognitive processes, including social skills such as interpretation of facial expressions, and skills developed for working with others in a specific team. Prior research had conceptualized skills as: 1) individual research skills; 2) generic teamwork skills; and 3) "this team" skills - skills developed through experience working with a specific team (Pennington, 2012, unpublished data). However, these conceptual models needed to be operationalized in ways that could be replicated and that provided a basis for measurement. Misra et al.'s (2015) research on the transdisciplinary orientation score (TDO) provided this mechanism. They separated transdisciplinary participant characteristics into conceptual skills and behavioral characteristics (CSB), and values, attitudes, beliefs (VAB). They defined CSB to include the ability to approach problems holistically from different vantage points; integrate concepts across perspectives; and communicate effectively with colleagues from other perspectives. The VAB dimension includes predisposition towards collaboration; openness towards learning other paradigms and worldviews; willingness to invest time; and beliefs about the benefits of collaboration compared with the costs. Misra et al. (2015) found that higher scores on the scale are significantly correlated with publication of ITD research articles with higher potential societal impact as judged by independent raters, and that higher scores are associated with experience in transdisciplinary research teams. CSB corresponds directly with most of the elements included in the original two EMBeRS process models. VAB expands the description of social and "this team" skills. The current EMBeRS systems model remains the same as originally reported (Pennington 2016). The BNO process model, however, has been revised to incorporate interpersonal skills and VAB more explicitly (Figure 2).

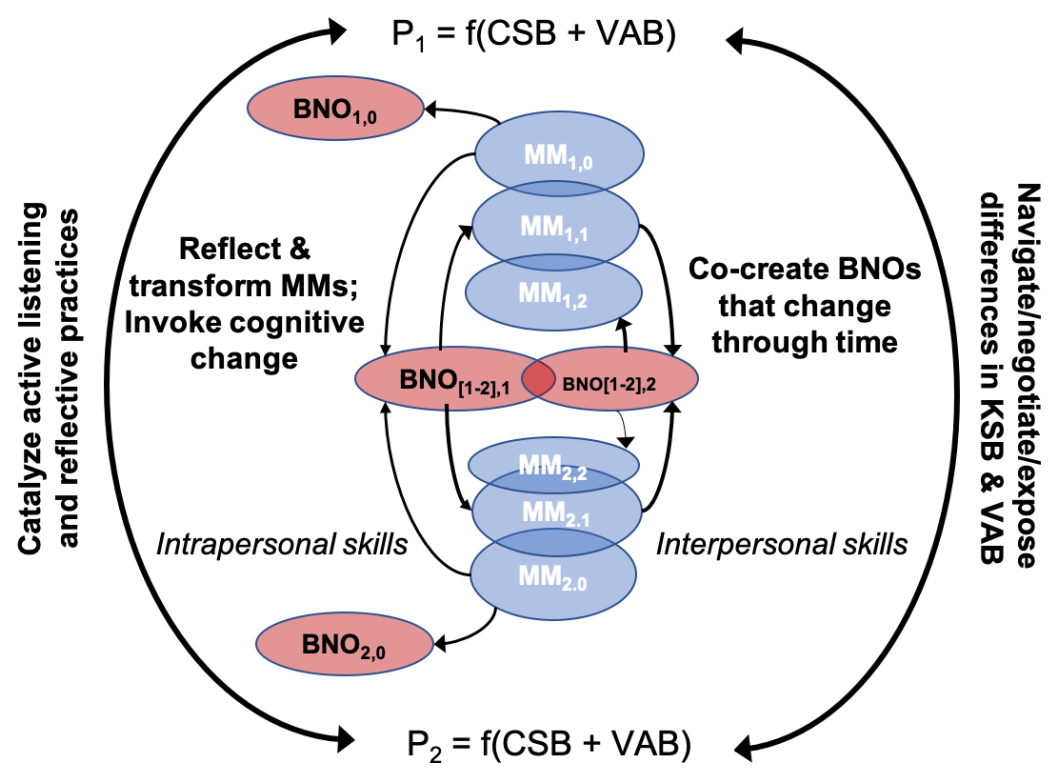

Figure 2: EMBeRS framework for progressively integrating knowledge using boundary negotiating objects (BNOs). Participants (P1 and P2) interact through (co)creating BNOs that capture their changing mental models (MM) of the problem as they reflect on their own and others' perspectives. The process is impacted by intrapersonal and interpersonal skills. 
Participants engage in a learner-centered, participatory, interactive process that involves co-creation of BNOs that are external representations of their mental models. During the process, a series of BNOs are co-created that unfold through time. There is explicit recognition that effective co-creation of BNOs depends on dynamic modification of individual mental models through active listening to other's perspectives, deep reflection on those perspectives, and reflective discourse that enables increased awareness of others' knowledge, expertise, goals, values, and dispositions. Therefore, individuals must have time to reflect and transform their mental models as an integral part of the activity. A key feature of the EMBeRS framework is the recognition that a given participant's mental model of a problem may not initially be well formed. Hence, each activity provides an opportunity for individuals to reflect on and organize their initial mental model $\left(\mathrm{MM}_{1,0}\right.$ and $\left.\mathrm{MM}_{2,0}\right)$, represent it $\left(\mathrm{BNO}_{1,0}\right.$ and $\left.\mathrm{BNO}_{2,0}\right)$, and explain it to the group, before engaging in group reflective discourse and co-creation of integrative $\mathrm{BNOs}\left(\mathrm{BNO}_{[1-2] .1}\right.$ and $\left.\mathrm{BNO}_{[1-2] .2}\right)$. This is facilitated to ensure every participant has an opportunity to organize and present their thinking. The framework, while focused primarily on cognitive processes, also recognizes that intrapersonal and interpersonal competencies impact the process.

The EMBeRS framework is generic and could be used during any group knowledge integration activity. Supplementary Material A provides detailed examples of four EMBeRS activities that were implemented in both workshops. In most cases, the activities are structured similarly:

1. Introduction

2. Individual work formulating a mental model and generating a BNO

3. Turn-taking (each individual shares their ideas with team members)

4. Teamwork formulating a shared model of the problem co-creating BNOs

5. Reflection and reflective discourse

An exception is the first activity in the Supplementary Material (A), which targets learning each other's research interests, and hence excludes the fourth step.

\section{Methods}

Two, intensive, 9 to 10-day EMBeRS workshops were implemented for multi-disciplinary doctoral students. The workshops were designed to teach ITD teamwork using place-based, case studies of water resources. Mexico City was selected as the focal case in 2016, and the Rio Grande watershed in 2017, both of which have complex water issues (Bojórquez-Tapia et al., 2019; Koch et al., 2019). Sequenced activities were developed following an inquiry approach to design (Alhadad \& Thompson, 2017; Thompson et al., 2016). A total of 25 individuals participated in the workshops (13 in 2016 and 12 in 2017). Participants were recruited from 86 National Science Foundation (NSF)-funded ITD research projects related to water. Participants were recruited who were from different projects and institutions to ensure they had no prior interactions with each other. Participants are described in more detail in Supplementary Material B.

Workshop design and implementation. The workshops were held July 11-22, 2016 (10 days excluding Saturday and Sunday) and June 8-16, 2017 (9 days including Saturday and Sunday) at the University of Texas at El Paso. Each day included one or more EMBeRS activities sequenced within three major segments: 1) generic learning and teamwork skills; 2) ITD problem-solving skills around the case study; and 3) activity design, leadership, and implementation (Table 1). Participants worked in a different team of three or four participants for each of the three segments, assigned to ensure maximum diversity of each group across disciplinary, race, gender, and institutional dimensions. In the 2016 workshop, each day typically began with a brief (less than 30 minute) introduction to the day's activites; a three-hour morning activity, and a three-hour afternoon activity (Table 1). Specific activities are described further below and in Supplementary Material A. Each day ended with group reflection on the activities of the day, including facilitated analysis of the design of the activity, what the design was intended to accomplish, and what it actually accomplished using a design framework (Goodyear \& Carvalho, 2014; Thompson et al., 2017). Each evening, participants were given a question about the day's activities to respond to through reflective writing (Boud, 2001). In addition, three times in 2016 and twice in 2017, participants were asked to write a page synthesizing information from three articles on food, energy and water to reveal longitudinal changes in their knowledge integration skills (Knight \& Thompson, 2018). The final day was dedicated to individual interviews and group reflection on the entire workshop. 
The second workshop was substantially revised based on feedback from the first workshop. Most activities were revised to provide a better process, based on what was learned to be effective during the first workshop. The second workshop ran through the weekend and several activities were combined or shortened to minimize the overall length of time. The focal place was switched to the Rio Grande watershed around El Paso to enable field trips involving direct engagement with stakeholders in the region, providing breaks from the intensity of the workshop while also exposing students to stakeholder perspectives. The sequencing of activities, in part dependent on presenter schedules, was modified for better flow. The design of the workshops and learning science research agenda are described in more detail in Thompson et al. (2017).

Table 1: Workshop design, showing sequence of activities. Activities are summarized in Table 2. Selected activities are described in detail in Supplementary Material A.

\begin{tabular}{|c|c|c|c|c|c|}
\hline \multicolumn{6}{|c|}{2016} \\
\hline & DAY 1 & DAY 2 & DAY 3 & DAY 4 & DAY 5 \\
\hline & Mon July 11 & Tues July 12 & Wed July 13 & Thurs July 14 & Fri July 15 \\
\hline AM & $\begin{array}{l}\text { Share Your } \\
\text { Research }\end{array}$ & Toolbox Dialogue $^{1}$ & $\begin{array}{l}\text { Explore the Problem } \\
\text { Space }\end{array}$ & Systems 1 & Stakeholder Analysis 1 \\
\hline \multirow[t]{3}{*}{ PM } & $\begin{array}{l}\text { Challenges of } \\
\text { Interdisciplinary } \\
\text { Research }\end{array}$ & $\begin{array}{l}\text { Dispositional } \\
\text { Characteristics }\end{array}$ & $\begin{array}{l}\text { Using SES } \\
\text { Frameworks }\end{array}$ & Systems 2 & Stakeholder Analysis 2 \\
\hline & DAY 6 & DAY 7 & DAY 8 & DAY 9 & DAY 10 \\
\hline & Sat July 18 & Sun July 19 & Mon July 20 & Tues July 21 & Wed July 22 \\
\hline AM & $\begin{array}{l}\text { Designing ID } \\
\text { Activities }\end{array}$ & Mock Solicitation 1 & $\begin{array}{l}\text { Groups: Activity } \\
\text { Development }\end{array}$ & $\begin{array}{l}\text { Sustainability Program } \\
\text { Design }\end{array}$ & $\begin{array}{l}\text { Interviews, group } \\
\text { reflection }\end{array}$ \\
\hline PM & $\begin{array}{l}\text { Groups: Activity } \\
\text { Development }\end{array}$ & Mock Solicitation 2 & $\begin{array}{l}\text { Groups: Activity } \\
\text { Development }\end{array}$ & Pilot activities & \\
\hline \multicolumn{6}{|c|}{2017} \\
\hline & $\begin{array}{l}\text { DAY } 1 \\
\text { Thurs Jun } 8 \\
\end{array}$ & $\begin{array}{l}\text { DAY } 2 \\
\text { Fri Jun } 9 \\
\end{array}$ & $\begin{array}{l}\text { DAY } 3 \\
\text { Sat June } 10 \\
\end{array}$ & $\begin{array}{l}\text { DAY } 4 \\
\text { Sun June } 11\end{array}$ & $\begin{array}{l}\text { DAY } 5 \\
\text { Mon Jun } 12 \\
\end{array}$ \\
\hline AM & $\begin{array}{l}\text { Challenges of } \\
\text { Interdisciplinary } \\
\text { Research }\end{array}$ & $\begin{array}{l}\text { Stakeholder field } \\
\text { trip: Civil } \\
\text { infrastructure }\end{array}$ & $\begin{array}{l}\text { Stakeholder field } \\
\text { trip: Farmers and } \\
\text { agriculture }\end{array}$ & $\begin{array}{l}\text { Stakeholder field trip: } \\
\text { Wetland restoration }\end{array}$ & $\begin{array}{l}\text { Stakeholder field trip: } \\
\text { Municipal } \\
\text { desalination }\end{array}$ \\
\hline \multirow[t]{2}{*}{ PM } & $\begin{array}{l}\text { Stakeholder } \\
\text { Analysis }\end{array}$ & $\begin{array}{l}\text { Dispositional } \\
\text { Characteristics }\end{array}$ & Toolbox Dialogue $^{1}$ & $\begin{array}{l}\text { Share Your Research; } \\
\text { Explore the Problem } \\
\text { Space } 1\end{array}$ & $\begin{array}{l}\text { Explore the Problem } \\
\text { Space 2; Using } \\
\text { standard frameworks }\end{array}$ \\
\hline & $\begin{array}{l}\text { DAY } 6 \\
\text { Tues Jun } 13\end{array}$ & $\begin{array}{l}\text { DAY } 7 \\
\text { Wed Jun } 14\end{array}$ & $\begin{array}{l}\text { DAY } 8 \\
\text { Thurs Jun } 15\end{array}$ & $\begin{array}{l}\text { DAY } 9 \\
\text { Fri Jun } 16\end{array}$ & \\
\hline AM & $\begin{array}{l}\text { Systems Thinking } \\
1 \& 2\end{array}$ & Mock Solicitation & $\begin{array}{l}\text { Groups: Activity } \\
\text { Design }\end{array}$ & $\begin{array}{l}\text { Interviews, group } \\
\text { reflection }\end{array}$ & \\
\hline PM & $\begin{array}{l}\text { Systems Thinking } \\
3 \& 4\end{array}$ & $\begin{array}{l}\text { Designing ID } \\
\text { activities }\end{array}$ & Pilot activities & & \\
\hline
\end{tabular}

${ }^{1}$ http://toolbox-project.org/

Activities employed the EMBeRS framework by iterating between individual and group reasoning (Figure 3 left and right quadrants) using one or more BNOs and focusing on CSBs and/or VABs (Figure 3 upper and lower quadrants,). Each individual brings unique CSBs and VABs to the team. Team members may initially have a range of awareness of each other's CSBs and VABs depending on prior interactions. Group concepts and skills are easily understood as the subjects of interest, methods of study, vocabulary, and other recognized features of disciplinary perspectives that must be combined into multidisciplinary, shared understandings of the problem. Group VAB can be understood as community culture. For example, disciplines differ in the degree to which qualitative and quantitative data are used. Each activity had a specific objective mapped to these individual and group CSB and VAB targets (Table 2 codes). The majority of activities focused on generating new individual and group concepts and new scientific narratives, with the ultimate goal of generating integrated research lines (Figure 3, upper quadrants). Share Your Research, Explore the Problem Space, Stakeholder Analysis, Using SES Frameworks, Systems Thinking, and Mock Solicitation are designed to generate more comprehensive, integrated mental models of the problem from a variety of perspectives, then progressively converge on a proposal for some aspect of the problem that the team could research together. These activities are described in more detail in Supplementary Material A. Three activities were included that focused directly on individual and group VAB. The Challenges of Interdisciplinary Research activity focuses on the motivations for choosing whether or not to 
engage in ITD. The Dispositional Characteristics activity targets exposing team members to differences in values, beliefs, actions, and feelings (Gosselin et al., 2020). The Toolbox Dialogue activity (http://toolbox-project.org/), which was designed by philosophers and not by the EMBeRS research team, targets exposing differences in epistemological assumptions across perspectives (Eigenbrode et al., 2007).

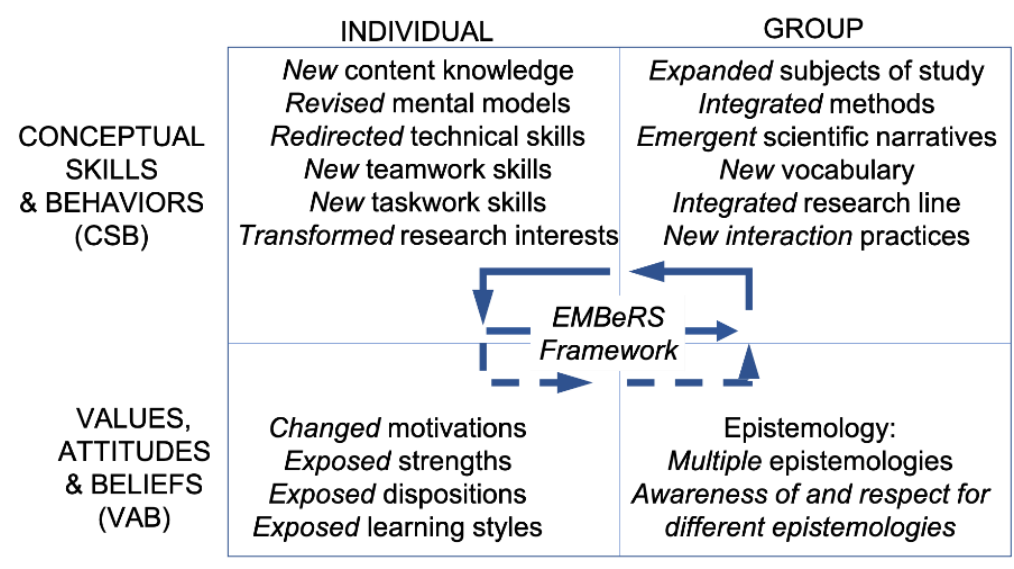

Figure 3: The EMBeRS Framework is used to design sequenced activities that iterate between representing individual mental models and co-creating group representations to negotiate shared mental models of the problem.

During the workshops, facilitators purposefully employed a variety of scaffolds, which are supporting structures that are gradually removed as knowledge and skills are gained. Scaffolds included instructor facilitation during teamwork, including prompting and timed turn-taking; reminders about active listening; and guidance regarding the construction of a particular BNO to be produced during an activity. Early team interactions were heavily facilitated, with regular post-activity reflective discourse that identified the behaviors being facilitated and reasons for incorporating those behaviors into the activity design. Facilitation was decreased through time as participants progressively monitored their own behaviors and interactions.

Data collection. Data were collected before, during, and after the workshops (Table 3 ) to investigate a variety of questions of interest. This article reports on the findings from analysis of the dynamic interplay between learning processes, (co)creation of BNOs, and knowledge integration. Two approaches were used. Learning scientists collected audio-video, visual representations, photographs, reflective writings, synthesis writings, and observer notes. In addition, an external evaluator conducted program evaluation, using a variety of survey and interview instruments. Human subject data were overseen by an Institutional Review Board at the University of Texas at El Paso.

BNOs. During the first half of the workshops many BNOs were constructed using concrete materials such as sheets of paper, markers, and sticky notes. Each of these was photographed. Some BNOs were captured with digital pens, if the team chose to use those. The Systems Thinking activities used computer software to generate BNOs.

Reflective Writing. Each evening, participants were given questions to reflect on and write about. Questions on day one and day six of both workshops provided an opportunity for students to reflect on the EMBeRS framework. Responses to these questions were coded thematically using a grounded-theory method (Corbin \& Strauss, 1990). Only participants who responded to questions on both days were included in the analysis.

Surveys. Participants completed three online surveys: a pre-program survey administered prior to the workshop, a post-program survey administered immediately following the workshop, and a follow-up survey administered nine months later. The pre-program survey included demographic questions, questions about their experiences working in ITD teams including challenges and barriers, and a question on what they hoped to gain from the workshop. The post-program survey included questions about the development of competencies to participate in an ITD team and questions to rate the value of each workshop activity. The follow-up survey asked the students how they have used the methods and skills in their own research, teaching, professional practice and discussions with others; and to list their presentations and publications that included workshop concepts/methods. 
Table 2: List of activities and their objective by segment. All segments included daily individual and group reflection. Activities are coded referencing the quadrants in Figure 3 that are targeted by the activity. Code: I-CSB = Individual CSB; I-VAB = Individual VAB; G-CSB = Group CSB; G-VAB = Group VAB. Detailed description of selected activities, denoted with * are available in Supplementary Material A. Design templates for most activities are available at http://embers.cybershare.utep.edu.

\begin{tabular}{|c|c|c|}
\hline Segment & Activity Name & Objective \\
\hline \multirow[t]{4}{*}{$\begin{array}{l}\text { Generic } \\
\text { Teamwork }\end{array}$} & *Share Your Research & $\begin{array}{l}\text { Learn other team members' research interests. Exposure to facilitated } \\
\text { participatory processes, active listening, reflection and reflective discourse, } \\
\text { and BNOs that are used in all EMBeRS activities. I-CSB; G-CSB }\end{array}$ \\
\hline & $\begin{array}{l}\text { Challenges of Interdisciplinary } \\
\text { Research }\end{array}$ & $\begin{array}{l}\text { Identify categories of ITD challenges being confronted and compare with } \\
\text { categories identified in the teamwork literature. Perception of challenges } \\
\text { depends on individual experiences. I-VAB }\end{array}$ \\
\hline & Dispositional Characteristics & $\begin{array}{l}\text { Increase awareness of differences in interaction styles based on individual } \\
\text { behavioral characteristics and motivational drivers. Increase knowledge of } \\
\text { self and its influence on interaction with others. Described in (Gosselin et al., } \\
\text { 2020). I-VAB }\end{array}$ \\
\hline & Toolbox Dialogue & $\begin{array}{l}\text { Expose differences in methodologies, epistemologies, and values across } \\
\text { individual perspectives and disciplines. Described in (Gosselin et al., 2020). I- } \\
\text { VAB; G-VAB }\end{array}$ \\
\hline \multirow[t]{8}{*}{ Case Study } & Stakeholder Analysis & $\begin{array}{l}\text { Identify the stakeholders in a problem area and the issues from their } \\
\text { perspectives. I-CSB }\end{array}$ \\
\hline & *Explore the Problem Space & $\begin{array}{l}\text { Map a wide range of concepts relevant to the problem to understand the } \\
\text { problem broadly and comprehensively. I-CSB; G-CSB }\end{array}$ \\
\hline & $\begin{array}{l}\text { *Using Socio-Environmental } \\
\text { System Frameworks }\end{array}$ & $\begin{array}{l}\text { Expose students to standard frameworks that have been used to structure } \\
\text { socio-environmental problems and map the problem into one framework. I- } \\
\text { CSB; G-CSB }\end{array}$ \\
\hline & Systems Thinking 1 & $\begin{array}{l}\text { Identify measurable properties of entities for which data could be collected. } \\
\text { I-CSB; G-CSB }\end{array}$ \\
\hline & Systems Thinking 2 & $\begin{array}{l}\text { Using Mental Modeler (Gray et al., 2014), map the relationships between } \\
\text { measurable properties and identify the type and strength of relationships } \\
\text { (positively or negatively correlated). I-CSB; G-CSB }\end{array}$ \\
\hline & Systems Thinking 3 & $\begin{array}{l}\text { Using Mental Modeler explore the impact on the system of increasing or } \\
\text { decreasing specific properties. I-CSB; G-CSB }\end{array}$ \\
\hline & Systems Thinking 4 & $\begin{array}{l}\text { Using Loopy (https://ncase.me/loopy/), create a causal loop diagram. I-CSB; } \\
\text { G-CSB }\end{array}$ \\
\hline & *Mock Solicitation & $\begin{array}{l}\text { Create an integrated conceptualization of an ITD research approach that } \\
\text { your team could propose in response to a solicitation. I-CSB; G-CSB }\end{array}$ \\
\hline \multirow[t]{4}{*}{ Leadership } & $\begin{array}{l}\text { Designing Interdisciplinary } \\
\text { Activities }\end{array}$ & $\begin{array}{l}\text { Review EMBeRS design principles, sources of ideas for participatory } \\
\text { activities, and considerations in modifying activities to more effectively } \\
\text { enable learning across disciplines. }\end{array}$ \\
\hline & $\begin{array}{l}\text { Developing Interdisciplinary } \\
\text { Activities }\end{array}$ & Practice collaboratively developing a new EMBeRS activity. \\
\hline & $\begin{array}{l}\text { Piloting Interdisciplinary } \\
\text { Activities }\end{array}$ & $\begin{array}{l}\text { Practice implementing an EMBeRS activity using workshop participants as } \\
\text { test subjects. }\end{array}$ \\
\hline & Sustainability Course Design & $\begin{array}{l}\text { Consideration of knowledge, skills, and attributes needed for SES research } \\
\text { and strategies for incorporating these into a course or program. }\end{array}$ \\
\hline
\end{tabular}

Interviews. Evaluation interviews were conducted with the students at the end of each workshop. In 2016, these interviews were conducted using videoconferencing and in 2017, in person. The interviews were semistructured and included open-ended questions about the students' overall experience in the workshop and the most important concepts, methods and insights they gained. The thirty-minute interviews were recorded and transcribed. Results from the 2016 cohort interviews were used to revise the post-program questionnaire for the 2017 cohort. The interview transcripts were coded thematically according to the method of Gibbs (2007). Themes for answers to each question were identified and coded by two independent coders and differences discussed and agreed upon. 
Table 3: Data types collected at doctoral workshops.

\begin{tabular}{|c|c|}
\hline Data type & Description \\
\hline Demographic data & Education level, discipline, gender, race, and ethnicity \\
\hline $\begin{array}{l}\text { Transdisciplinary } \\
\text { Orientation (TDO) Score }\end{array}$ & $\begin{array}{l}\text { This validated score measures change along two dimensions: } 1 \text { ) values, attitudes, and beliefs } \\
\text { (VAB) toward teamwork; and 2) conceptual skills and behaviors (CSB) for engaging in } \\
\text { teamwork (Misra et al., 2015). Not discovered by the EMBeRS team until after the } 2016 \\
\text { workshop, it was given pre- and post-workshop in the } 2017 \text { workshop only. }\end{array}$ \\
\hline Trimetrix $^{\circledast}$ & $\begin{array}{l}\text { Measures dispositional characteristics of individuals. These data are used to guide } \\
\text { participants' abilities to navigate and negotiate differences in attitudes and behaviors during } \\
\text { teamwork. }\end{array}$ \\
\hline Audio-video (AV) & $\begin{array}{l}\text { Digital pens record audio during teamwork and are combined with video to capture team } \\
\text { interaction }\end{array}$ \\
\hline Photographs of BNOs & Visual diagrams produced by individuals and co-created during teamwork. \\
\hline $\begin{array}{l}\text { Retrospective Pre- and } \\
\text { Post-Evaluation (RPPE) }\end{array}$ & Post-activity self-assessment by individuals. \\
\hline Reflective writing & Nightly response to one or two questions related to the day's activities. \\
\hline Synthesis writing & $\begin{array}{l}\text { The last activity (Mock Solicitation) requires teams to produce an integrated proposal in } \\
\text { response to a brief, authentic solicitation. }\end{array}$ \\
\hline Surveys & Pre- and post-workshop surveys; follow up surveys nine months after the final workshop. \\
\hline Interviews & Thirty minute individual interviews at the end of each workshop. \\
\hline
\end{tabular}

\section{Results}

The multi-modal data analysis has aimed to address the complexity of interdisciplinary learning in these groups. Thus far, analyses of these data have contributed to understanding scaffolds for interdisciplinary writing (Knight \& Thompson, 2018, 2020); scaffolds for collaboration capacity (Gosselin et al., 2020); and strategies for assessing the degree of interdisciplinarity of teamwork products (Thompson et al., 2020). This article presents new results from analysis of the TDO survey, photographs of BNOs, reflective writing, surveys, and interviews. Section 4.1 presents an example analysis of BNOs produced by one group in 2017. Section 4.2 presents results from the TDO survey, which was only administered in 2017. Section 4.3 presents results from the pre- and post-workshop surveys and interviews from both years. Section 4.4. presents results from analysis of the nightly reflective writing from both years.

\subsection{Results from analysis of audio-video, visual, and textual data}

The following focuses on analysis of the BNOs created by one of the teams (Group 2) in 2017, selected because they successfully produced a final research proposal that was assessed as interdisciplinary. Similar analyses were conducted on all of the group BNOs from both years.

Individuals in Group 2 produced concept maps to describe their own research during the Share Your Research activity on day 4 of the workshop (Figure 4). These BNOs were used to facilitate explanation of each individual's research, clarify the boundaries of that research, and enable other team members to identify potential connections with their own research - negotiating preliminary connections across disciplines. It can be seen that all students used sticky notes to identify key ideas and then drew lines to connect these ideas. In organizing their representation of their research, they had the flexibility to move these ideas around in a way that aided communication of their topic. Michael has focused more on grouping concepts whereas Katharine seems more concerned about the process. In Lauren's map, the lines connecting ideas are questions - such as "How do we educate people to be sustainable?".

The concept maps included in Figure 4 also show the different focus area of these three students. All three have framed their research around climate change (see A tagged in each concept map). Michael's focus is on agriculture and the socio-political context (B) that will ensure outcomes such as sustainability and food supply (C). Katharine's map demonstrated the focus on infrastructure and impacts on built infrastructure (D). In 
Lauren's concept map, there is more emphasis on human factors, social/environmental justice and education (E) than the others.

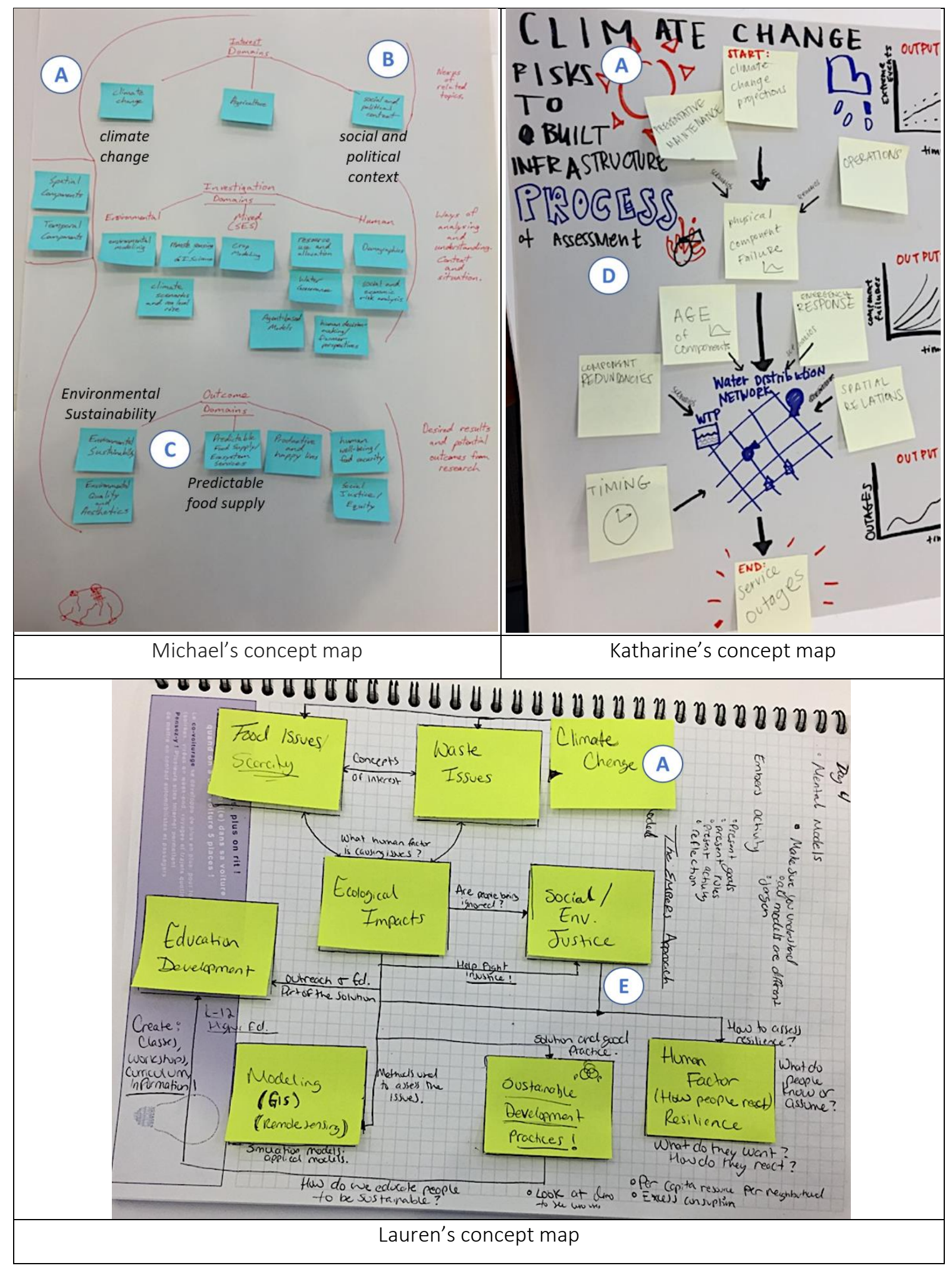

Figure 4: Concept maps of individual research for students in Group 2. Letters refer to concepts that connect across BNOs produced by individuals and through time, and are explained in the text. 
That evening the students were given the following prompt for their reflective writing:

Look again at a concept map that you worked on today. Are there more concepts or connections you would like to add? Is there anything you want to change - if so, why? What were the main ideas that you found important today, and does the map represent them appropriately?

Michael identified the following role for the concept map:

"it seems like the goal here is to provide everyone with enough understanding of your research to connect to it, learn from it, integrate it, without getting too bogged down in the nitty-gritty details of disciplinary assumptions, jargon, or misgivings."

Katharine realized that her concept map did not communicate her values when telling the story of her research:

"I would like to change my concept map to be of a different type. Currently it is in the form of a process flow diagram whereas I would like to change it to be one of a grouping of concepts behind my motivations, research questions, and research methods. The process flow diagram helped me to identify all of my individual topics of research and their connections to lead to the end outcome of the research, but my values are hidden within it."

Lauren identified two different uses for the concept map:

"Putting all my ideas down and finding how things connected or related allowed me to think of a more clear topic I could potentially research. It also helped that my group could ask me questions and essentially make a topic more clear or by creating research questions from my basic ideas. I am not sure I would add or change my concepts or connections but I am sure if I conducted the same exercise my concept map would be different."

In subsequent activities, the groups were asked to produce other representations that served as different perspectives on the problem, contributing to their understanding of the water issues in the El Paso area (Figure 5).

The stakeholder map was produced on the first day to prepare the students for the stakeholder field trips, before the construction of the individual concept maps or more explicit explanation of the role of BNOs. While it was a requirement to produce the map as part of the activities, it can be seen that Group 2 did not create a complex representation, and given the lack of detail, it seems unlikely that this diagram provided support as a BNO.

On day 5, during the Using Standard Frameworks activity, students were presented with a number of types of representation commonly used by the scientific community and were asked to apply several to the case study. Initially they worked individually representing their own mental model using at least one of the representations. Then they worked together co-creating multiple representations (Figure 5). The co-created representations sometimes reflected parts of the initial individual representations, but often resulted in new, synergistic representations - providing opportunities for the students to reflect on their previous mental models and revise these. Creating and moving post-it notes provided an artefact around which to have a conversation and negotiate the position in the group's understanding of the system. Without these conversations, new understandings of connections between climate change, water, sectors (including agriculture), infrastructure, and human factors would have been far more challenging for any of the individuals in this group. Group 2 chose a Drivers Pressures States Impacts Responses diagram (DPSIR) (Bell, 2012), a socio-ecological systems (SES) model (Ostrom, 2007) and an issues map (Yokohata et al., 2019). The representations are also comprised of paper (with lines and words drawn) and sticky-notes. In the issues map and the SES framework, the sticky notes represent those ideas that were being negotiated in that group, whereas the boxes (particularly in the SES framework) are more fixed (and non-negotiable within the group). An example of this is Resource Units (F) with 'groundwater', 'surface water' and 'reclaimed water' on sticky notes (G). In particular, the issues map has no writing on the paper, with the position and grouping of the issues left to negotiation within the group during the remainder of the workshop (used for several days). They included:

- Water impacts (scenarios) [which are related to Climate scenarios (drought) and state power scenarios]

- Farmers, Native Americans and City managers/treatment/distribution [related to infrastructure failure scenarios]

- Neighborhoods/citizens

- Small businesses and large businesses [related to water/person/business analysis 
- Rio Bosque

- IBWC

- Mexico [related to stakeholder survey (matrix) (people); baseline indicators; livelihood indicator; spatially explicit supply/demand and strategic planning]

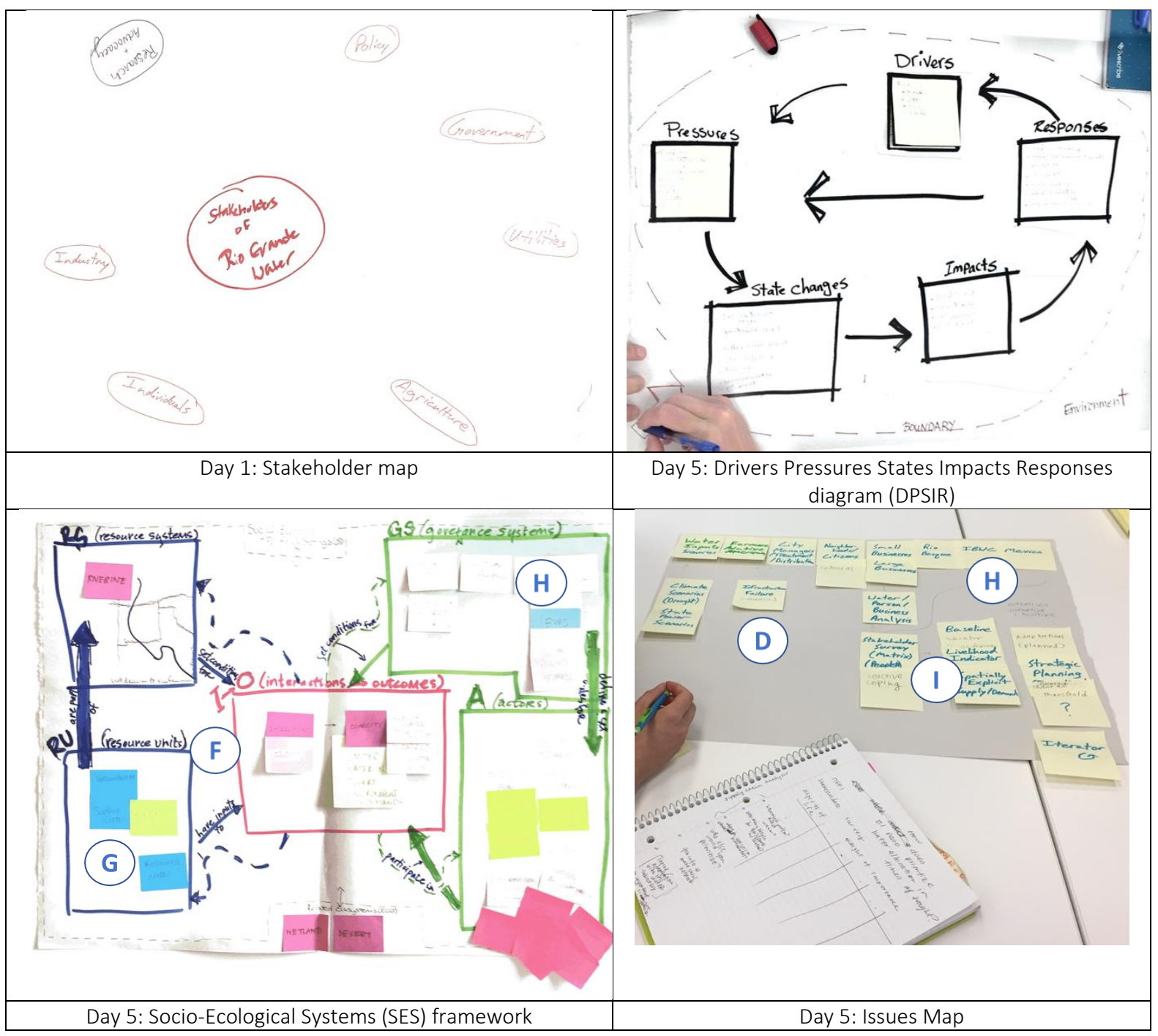

Figure 5: Four different types of representations co-created by Group 2. Letters refer to concepts that connect across BNOs produced by individuals and through time, and are explained in the text.

These issues show overlap between co-created representations (for example IBWC is seen on both the SES and issues map $(\mathrm{H})$ ) and also between the issues map and individuals' concept maps (for example infrastructure from Katharine's original concept map (D)).

On day 6 students were asked to produce a systems model using an online tool called Mental Modeler (Gray et al., 2014). In order to produce this representation, students were required to learn the software. Due to the nature of the software used, only one student could edit the map at a time. Students engaged in a different type of collaboration at this stage - either through turn-taking or by giving directions and contributing ideas while the student interacting with the software had control over the creation of the systems model.

On day 7 students were asked to develop a short group proposal during the Mock Solicitation activity. All groups presented their proposal at the end of the activity. In Group 2, they used a highly revised version of their systems diagram from day 6 (Figure 6). In this version of the diagram relationships between the three BNOs co-created on day 5 (Figure 5 ) have been retained. From the SES model in Figure 5 , surface water has been selected as a 
key factor (Figure $6 \mathrm{G}$ ). Also from the SES model, infrastructure failure is an important factor in water availability (Figure 6D). The user groups identified in the issues map in Figure 5 are now all linked to the livelihood indicator (Figure 6I). There are also new ideas included in this system model such as economic demand, resident demand and total demand per capita (J). The systems model and the final proposal explicitly reflect portions of the system related to their integrated research interests.

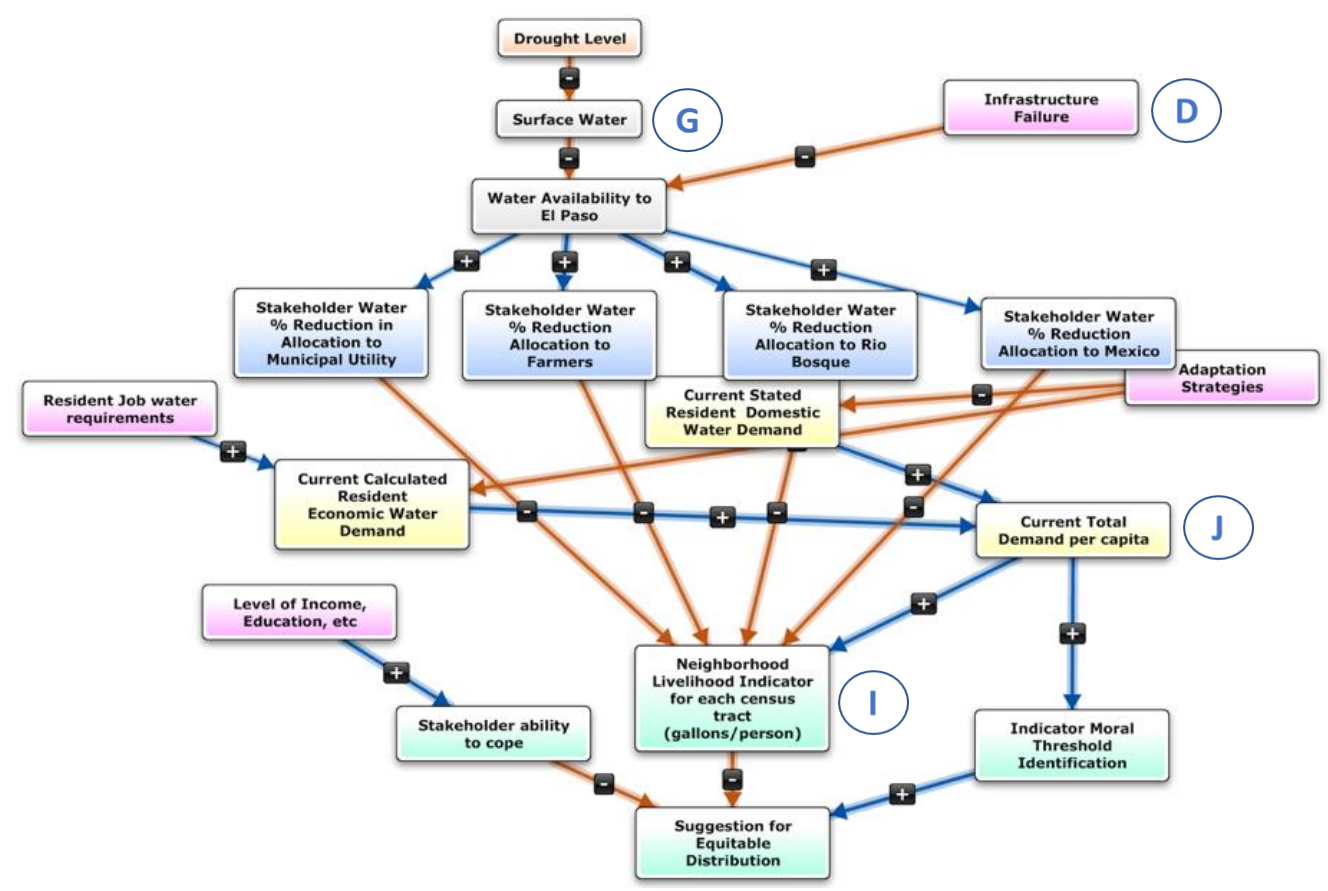

Figure 6: Systems model of water issues constructed using the Mental Modeler online tool. All the relationships between the boxes have a value assigned in a causal relationship (and the boxes and lines are also color-coded to reflect this).

\subsection{Results from 2017 transdisciplinary orientation survey}

The twelve doctoral students who participated in the 2017 EMBeRS Workshop completed the TDO (transdisciplinary orientation) scale instrument before the workshop and again after the workshop. Scores were assigned using a 5-item scale for each of the twelve questions: strongly agree=4, agree=3, neutral=2, disagree=1, strongly disagree $=0$. The maximum score is 48 . Ten of the twelve students had gains in TDO scores. Two had scores that remained the same before and after the workshop-one of these had an almost perfect score before the workshop and the other had the lowest TDO score both before and after the workshop. The gains in scores ranged from $2 \%$ to $31 \%$. The overall group score increased by $10 \%$. Interestingly, the students with self-reported higher levels of experience in ITD research showed the greatest average increase: $11 \%$ compared with $9 \%$ for those with moderate experience and $2 \%$ for the one student with low experience.

The Wilcoxon signed-ranks test compared TDO scores before and after participating in the workshop. These data indicate that workshop participants' TDO scores were significantly higher after the workshop $(M d n=47)$ than before the workshop ( $M d n=41), z=-2.81, p<0.005, r=-0.57$ (a large effect size).

Each TDO category, CSB and VAB, is positively correlated with six items in the survey. The influence of participation in the workshop was significant for both dimensions of TDO, although the effect was greater for the CSB dimension: pre-program ( $M d n=20)$, post-program $(M d n=24) ; z=-2.82, p<0.005, r=-0.58)$ than for the VAB dimension: pre-program $(M d n=23)$, post-program $(M d n=24) ; z=-2.32, p<0.05, r=-0.46)$. This may reflect that participants were recruited from interdisciplinary research projects and may have already had VABs oriented towards transdisciplinary research. 


\subsection{Results from other surveys and interviews}

Confidence in specific competencies development. The post program survey for the 2017 cohort only, included questions on participants' confidence in sixteen specific topic areas covered in the workshop. Table 4 lists nine directly related to integrating knowledge across disciplines. The majority of participants were confident or highly confident that they had developed abilities to engage effectively to develop integrated conceptual models and research questions, and that they had developed understanding of how to integrate different perspectives. The most difficult competencies for the participants were communicating their own disciplinary knowledge to others and modifying their own research in response to engagement with different disciplinary perspectives.

Overall impact. Approximately thirty-minute evaluation interviews were conducted with each participant of both cohorts on the last day of each workshop. Questions for both cohorts included: 1) describe the overall experience; 2) what influenced you the most; 3) what stands out as most important for you and your career plans; 4) what are your career plans and how have they been influenced by the workshop; 5) how can we improve the workshop? Two additional questions were added for the 2017 cohort: 6) did you experience any extraordinary incidences; and 7) did novelty emerge and if so, how? Selected quotes from surveys and interviews are provided in Supplementary Material C.

All participants from both cohorts discussed gaining insights into and skills for participating in, leading and teaching ITD research teams as an outcome of their participation. Many mentioned the specific competencies included in Table 4. Additional outcomes related to integrating knowledge across disciplines include:

- $\quad$ Enhanced understanding of multiple perspectives/disciplines and appreciation for how diverse fields contribute to ITD research.

- $\quad$ Enhanced skills in framing ITD research questions.

- Improved skills in communicating about ITD research.

- Increased knowledge of and expanded skills in diverse problem-solving techniques, tools and methods for facilitating ITD research.

Table 4: Confidence in conceptual understanding, abilities and skills related to integrating knowledge across disciplines ( $n=12$ ).

\begin{tabular}{|c|c|c|c|c|}
\hline Outcome & Highly confident & Confident & $\begin{array}{l}\text { Moderately } \\
\text { confident }\end{array}$ & $\begin{array}{c}\text { Minimally/not all } \\
\text { confident } \\
\end{array}$ \\
\hline $\begin{array}{l}\text { Ability to identify linkages } \\
\text { between perspectives. }\end{array}$ & $50 \%$ & $50 \%$ & - & - \\
\hline $\begin{array}{l}\text { Ability to co-develop integrated } \\
\text { conceptual models. }\end{array}$ & $50 \%$ & $42 \%$ & $8 \%$ & - \\
\hline $\begin{array}{l}\text { Ability to capitalize on the } \\
\text { strengths of different researchers. }\end{array}$ & $50 \%$ & $42 \%$ & $8 \%$ & \\
\hline $\begin{array}{l}\text { Ability to co-develop integrated } \\
\text { research questions. }\end{array}$ & $42 \%$ & $58 \%$ & - & - \\
\hline $\begin{array}{l}\text { Ability to communicate across } \\
\text { disciplinary boundaries. }\end{array}$ & $42 \%$ & $58 \%$ & - & - \\
\hline $\begin{array}{l}\text { Ability to share research in } \\
\text { language meaningful to those } \\
\text { outside your discipline. }\end{array}$ & $33 \%$ & $50 \%$ & $17 \%$ & - \\
\hline $\begin{array}{l}\text { Skills in engaging colleagues from } \\
\text { other disciplines to gain their } \\
\text { perspectives. }\end{array}$ & $50 \%$ & $50 \%$ & - & - \\
\hline $\begin{array}{l}\text { Skills in developing boundary } \\
\text { negotiating objects that } \\
\text { effectively represent multiple } \\
\text { points of view. }\end{array}$ & $42 \%$ & $58 \%$ & - & - \\
\hline $\begin{array}{l}\text { Skills in modifying your research } \\
\text { in response to interactions with } \\
\text { other perspectives. }\end{array}$ & $33 \%$ & $50 \%$ & $17 \%$ & - \\
\hline
\end{tabular}


In response to the questions about what they found extraordinary about their workshop experience, the 2017 cohort highlighted two aspects: 1 ) they all came to respect and trust each other, which allowed them to effectively integrate individual personalities and strengths, perspectives and disciplines; and 2) the experience gave them the confidence to better understand and articulate their own ideas. The most common response to what they found novel was how the workshop broadened their perspectives and helped them develop understanding of how to effectively negotiate and compromise to develop shared understanding and consensus.

Follow-up surveys were conducted with both cohorts approximately nine months after the workshops to learn how the participants were using what they had learned. All reported using the knowledge, skills, and methods in a wide diversity of applications: developing and communicating their dissertation research plans; preparing collaborative research proposals; working with teams and stakeholders engaged in current transdisciplinary research projects; and in everyday communications with colleagues. Many included developing new activities that apply the EMBeRS framework in the undergraduate and graduate courses they teach. Three are developing new courses that will focus on teaching the EMBeRS framework. Several reported the value of the EMBeRS approach in planning and presenting their own research and discussed using the approach successfully in a diverse array of transdisciplinary research projects and proposals.

Many students have remained in contact with the principal investigator through email, and consistently remark that they are finding the methods and tools they gained from the EMBeRS workshop useful in a wide variety of ways. Clearly, not only was the training impactful in the way intended but it also stimulated creative thinking about other ways the approach could be used and transferred to other contexts. As noted above, participant's practices are changing as well, and these changes have led to a number of impacts on how they conduct their work, although it is too soon to assess long-term impact on their ability to work on SES research teams or the products of such work. Nevertheless, improving the ability of doctoral students to transform their mental models to accommodate different disciplinary perspectives in a workshop setting is likely to translate to improvements in their ability to do so in a real context

The reported enthusiastic and frequent use of the EMBeRS framework by the workshop participants in a variety of aspects of their professional lives provides strong evidence of its value and usefulness. Some participants have co-written two articles supporting the framework and encouraging its use, especially in graduate education (Killion et al., 2018; Pennington et al., 2018).

\subsection{Results from reflective writing}

The reflective writings on days one and six provided an opportunity for participants to identify what they perceived as the most useful knowledge and skills associated with the EMBeRS framework. There were a total of forty one reflective writings from days one and six. Only reflections from participants who responded both days were included in the analysis. This resulted in sixteen reflections from eight participants in 2016, and twenty reflections from ten participants from 2017, for a total of thirty six reflective writings. Thirty three thematic areas were identified across both days (Supplemental Material D). For each theme, reflective writings were counted that referred to that theme at least once. Results were sorted by the number of usages. The most frequently used terms across both cohorts were: BNOs, diverse ideas, and communication/dialogue. Other frequently used terms included: shared model, integrating/synthesizing, references to a specific BNO, iteration, and mental models. Remaining terms reflect a wide range of action verbs and descriptors. Results from the two cohorts were compared, although direct comparisons are not possible due to the different numbers of writings included in the analysis. In general, the 2017 cohort used more technical and process-focused verbiage. For example, the 2016 cohort only mentioned BNOs in seven reflective writings compared with eighteen for the 2017 cohort. Integration and synthesis were mentioned in only four reflective writings in 2016 compared with nine in 2017. Mental models were mentioned in only one reflective writing from 2016 compared with nine reflective writings in 2017. Increased fluency about knowledge integration processes in the 2017 cohort might be attributed to increased focus on process during the workshop compared with the 2016 workshop. 


\section{Discussion}

The EMBeRS workshops were designed to achieve two outcomes: 1) develop skills for integrating knowledge across perspectives in SES research; and 2) an exploratory test of the role of BNOs in learning across perspectives. This represents two aspects of current research on collaborative learning identified in Schneider et al. (2021) - research on learning to collaborate and research on learning while collaborating. Based on prior research reported in Pennington et al. (2016), initial focus was on the BNOs themselves, with questions of interest regarding what makes an effective BNO, whether this changes through time and extended interactions, and what practices and skills lead to generation of an effective BNO. While it was obvious that a participatory process was needed, that was not initially the focus. During the 2016 workshop it became apparent that an effective BNO depended on an effective process for generating BNOs, consistent with longstanding models of teamwork that focus on inputs, mediating factors (processes), and outputs (McGrath 1964; Hackman \& Morris 1975; Marks et al. 2001). Hence, the activities in the 2017 workshop were re-designed with careful attention to aspects of the process. In addition, the Misra et al. (2015) article developing the TDO scale focused attention on processes addressing CSB and VAB. At its core, the EMBeRS framework is designed to enable changes in CSB. However, the framework has evolved extensively through time as more has been learned about the dynamic interplay between learning across perspectives, reasoning with BNOs, and the VAB issues that impact those processes. This is consistent with a recent meta-analysis of research on team effectiveness that found that team learning occurs at the intersection of structural features of the team (task, technology, etc.), mediating mechanisms such as information sharing, and compositional features of team members such as personality differences (Mathieu et al. 2019). Guimarães et al. (2019) studied characteristics of researchers engaged in team research and generated a comprehensive list, many of which are VABs.

The role of BNOs in mediating these processes is that as BNOs are created and revisions to mental models take place, the BNOs are flexible enough to be carried forward and used to initiate negotiation on the next iteration. This can continue as different perspectives are incorporated into the development of an integrated research proposal. The early use of concept maps facilitates this. They were initially developed by individuals to communicate their expertise to the team. In progressing through the tasks, concept maps are revised and combined in order to explore and define the problem space. Other options for representing the problem space are subsequently offered to students (such as stakeholder mapping or simulation modelling), but the series of concept mapping activities are key for generating shared understanding of the problem and expertise of team members. Finally, the participants create final, stable representations combined with text in the form of a research proposal (Thompson et al., 2020). Although there has long been recognition that boundary objects play a critical role in mediating groupwork across perspectives, few have focused on their evolution through time. Fiore and Schooler (2004) recognized that representational tools act as scaffolding for building a shared representation of a problem. Ewenstein and Whyte (2009) distinguished between boundary objects as being relatively stable representations of knowledge and what they called epistemic objects that are in flux and unfold through time. Fiore and Wiltshire (2016) synthesize multiple lines of research on team cognition and generate an integrated view of cognitive offloading and scaffolding through representational artifacts. Hall et al. (2018) note that while effective team functioning depends on team processes that generate emergent states, only a few relevant concepts have been studied especially with respect to cognition.

This research was limited by the small number of participants (25) and cohorts (2). More workshops are needed as well as testing in different contexts to improve the evidence base, extend the generality of the approach, and also develop more and different kinds of activities across different topics. Investigations of how this training impacts the ability of real ITD teams to frame SES problems, and how that, in turn, propagates through the rest of the SES modeling process, will be critical for demonstrating long term impacts from the approach.

The EMBeRS activities developed in the workshops have been successfully translated to a semester-long course at University of Texas at El Paso. Elements have been applied to the design of other courses focused on training practitioners to work in interdisciplinary teams (Thompson et al., 2018). The longer time frame of a course lessens (but does not remove) the intensity of the training experience while delivering similar results (according to the TDO survey and informal student feedback). However, there are benefits to the workshop approach. Participants were hand selected to achieve a level of diversity that cannot be controlled in a regular course. Because recruitment was a competitive process through large, water-related SES research projects, participants were already predisposed towards SES collaboration and motivated to gain these skills. In addition, workshop participants highly valued the opportunity to engage deeply with students from other institutions with similar goals, developing a widespread network of peers. 
As of the writing of this discussion, a pandemic is occurring and most academic work has been transitioned to remote. Online activities are being designed to attempt to deliver the same positive outcomes as face-to-face activities. A half-day online workshop occurred at the end of July 2020 and in October 2020. In addition, the semester-long graduate course was taught entirely online August through November 2020. Preliminary assessment indicates the online activities were effective in many of the same ways as the face-to-face workshops, although engagement and reflective discussion were more difficult.

As society continues to seek input from scientists on a wide range of challenging socio-environmental issues, it is critical that training opportunities become more pervasive throughout the academic and research communities. Cheruvelil et al. (2014) argue that graduate programs should offer seminars, workshops, or entire courses on how to effectively collaborate in science, and this argument was also made in Killion et al. (2018). Klein (2020) notes that training approaches typically considered as professional development (for example, workshops) are beginning to be incorporated into formal classes. While there are a growing number of useful resources for providing team science training (e.g. Toolbox Dialogue: http://toolbox-project.org/; Team Science Toolkit: https://www.teamsciencetoolkit.cancer.gov; Integration \& Implementation Science Resources: http://i2s.anu.edu.au/resources; and TDnet: https://naturalsciences.ch/topics/co-producing_knowledge /methods), the EMBeRS framework is unique in the team science body of literature in that it provides an effective process-oriented approach supporting social learning and knowledge integration.

\section{Conclusion}

A critical component for SES research and modeling is the development of inter- and transdisciplinary problem conceptualizations that are shared among team members. The EMBeRS framework targets the specific challenge of integrating knowledge across perspectives to achieve this outcome. The framework embeds co-creation of boundary negotiating objects in a structured negotiation process that emphasizes learning across perspectives as a precursor to knowledge integration. Analysis of products from the workshops demonstrates convergence on integrated problem conceptualizations. Qualitative and quantitative data, including reflections from instructors and workshop participants, strongly suggest that the EMBeRS framework is highly impactful for achieving this. Short- and medium-term outcomes have been promising. Participants in the EMBeRS doctoral workshops indicate that the experience was transformative, providing knowledge and skills unavailable elsewhere, filling gaps in their programs, and improving their confidence in their capacity for inter- and transdisciplinary research. Pre- and post-workshop surveys confirm that the experience changed participants' knowledge, behaviors, and competencies for engaging across disciplines. Many participants reported that they have used the framework in a variety of research and education settings, indicating they are able to transfer their new competencies to other contexts. Participants have not only used the framework in their own work, they have reported actively disseminating it to others within their sphere of influence. As the SES research community continues to address the complex problems confronting society, new approaches that achieve these kinds of outcomes are urgently needed.

\section{Acknowledgements}

This material is based upon work supported by the National Science Foundation under grant numbers DGE1545404, OCl-1135525, OCl-0753336, and OCl-0636317. It was also supported by the National SocioEnvironmental Synthesis Center (SESYNC) under funding received from the National Science Foundation under grant number DBI-1052875 and from institutional resources through the University of Texas at El Paso and Griffith University in Australia. The authors also would like to acknowledge ideas contributed by Drs. Gabriele Bammer, Roderic Parnell, Antje Danielson, and Geoffrey Habron that have informed this material. Ph.D. student Penny Wheeler was instrumental in much of the data collection during the 2017 workshop. 


\section{References}

Alhadad, S. S. J., \& Thompson, K. (2017). Understanding the mediating role of teacher inquiry when connecting learning analytics with design for learning. Interaction Design and Architecture(s), 33, 54-74.

Anthony, L. J., Palius, M. F., Maher, C. A., \& Moghe, P. V. (2007). Using Discourse Analysis to Study a Cross-Disciplinary Learning Community: Insights from an IGERT Training Program. Journal of Engineering Education, 96(2), 141-156. https://doi.org/10.1002/j.2168-9830.2007.tb00924.x

Argent, R. M., Sojda, R. S., Guipponi, C., McIntosh, B., Voinov, A. A., \& Maier, H. R. (2016). Best practices for conceptual modelling in environmental planning and management. Environmental Modelling \& Software, 80, $113-121$. http://www.sciencedirect.com/science/article/pii/S1364815216300433

Badham, J., Elsawah, S., Guillaume, J. H. A., Hamilton, S. H., Hunt, R. J., Jakeman, A. J., Pierce, S. A., Snow, V. O., BabbarSebens, M., Fu, B., Gober, P., Hill, M. C., Iwanaga, T., Loucks, D. P., Merritt, W. S., Peckham, S. D., Richmond, A. K., Zare, F., Ames, D., \& Bammer, G. (2019). Effective modeling for Integrated Water Resource Management: A guide to contextual practices by phases and steps and future opportunities. Environmental Modelling \& Software, 116, 4056. https://doi.org/10.1016/j.envsoft.2019.02.013

Bell, S. (2012). DPSIR = A Problem Structuring Method? An exploration from the "Imagine" approach. European Journal of Operational Research, 222(2), 350-360. https://doi.org/10.1016/j.ejor.2012.04.029

Bojórquez-Tapia, L. A., Janssen, M., Eakin, H., Baeza, A., Serrano-Candela, F., Gómez-Priego, P., \& Miquelajauregui, Y. (2019). Spatially-explicit simulation of two-way coupling of complex socio-environmental systems: Socio-hydrological risk and decision making in Mexico City. Socio-Environmental Systems Modelling, 1, 16129-16129. https://doi.org/10.18174/sesmo.2019a16129

Borrego, M., Boden, D., \& Newswander, L. K. (2014). Sustained Change: Institutionalizing Interdisciplinary Graduate Education. The Journal of Higher Education, 85(6), 858-885. https://doi.org/10.1080/00221546.2014.11777350

Boud, D. (2001). Using journal writing to enhance reflective practice. New Directions for Adult and Continuing Education, 2001(90), 9. https://doi.org/10.1002/ace.16

Bransford, J., Vye, N., Stevens, R., Kuhl, P., Schwartz, D., Bell, P., Meltzoff, A., Barron, B., Pea, R., Reeves, B., Roschelle, J., \& Sabelli, N. (2006). Learning theories and education: Toward a decade of synergy. In Handbook of Educational Psychology (P. Alexander\&P. Winne (Eds.), Vol. 2, pp. 209-244). Lawrence Erlbaum Associates.

Cairns, R., Hielscher, S., \& Light, A. (2020). Collaboration, creativity, conflict and chaos: Doing interdisciplinary sustainability research. Sustainability Science. https://doi.org/10.1007/s11625-020-00784-z

Cheruvelil, K. S., Soranno, P. A., Weathers, K. C., Hanson, P. C., Goring, S. J., Filstrup, C. T., \& Read, E. K. (2014). Creating and maintaining high-performing collaborative research teams: The importance of diversity and interpersonal skills. Frontiers in Ecology and the Environment, 12(1), 31-38. https://doi.org/10.1890/130001

Corbin, A., \& Strauss, A. (1990). Grounded theory research: Procedures, canons, and evaluative criteria. Qualitative Sociology, 13(1), 3-21. URL

de Kraker, J., Kroeze, C., \& Kirschner, P. (2011). Computer models as social learning tools in participatory integrated assessment. International Journal of Agricultural Sustainability, 9(2), 297-309. https://doi.org/10.1080/14735903.2011.582356

Eigenbrode, S. D., O'Rourke, M., Wulfhorst, J. D., Althoff, D. M., Goldberg, C. S., Merrill, K., Morse, W., Nielsen-Pincus, M., Stephens, J., Winowiecki, L., \& Bosque-Perez, N. A. (2007). Employing Philosophical Dialogue in Collaborative Science. BioScience, 57(1), 55-64. https://doi.org/10.1641/B570109

Elsawah, S., Filatova, T., Jakeman, A. J., Kettner, A. J., Zellner, M. L., Athanasiadis, I. N., Hamilton, S. H., Axtell, R. L., Brown, D. G., Gilligan, J. M., Janssen, M. A., Robinson, D. T., Rozenberg, J., Ullah, I. I. T., \& Lade, S. J. (2020). Eight grand challenges in socio-environmental systems modeling. Socio-Environmental Systems Modelling, 2, 16226-16226. https://doi.org/10.18174/sesmo.2020a16226

Ernst, A. (2019). Review of factors influencing social learning within participatory environmental governance. Ecology and Society, 24(1). https://doi.org/10.5751/ES-10599-240103

Ewenstein, B., \& Whyte, J. (2009). Knowledge practices in design: The role of visual representations as 'epistemic objects.' Organization Studies, 30: 7-30.

Fernández-Giménez, M. E., Augustine, D. J., Porensky, L. M., Wilmer, H., Derner, J. D., Briske, D. D., \& Stewart, M. O. (2019). Complexity fosters learning in collaborative adaptive management. Ecology and Society, 24(2), art29. https://doi.org/10.5751/ES-10963-240229

Fiore, S. M., Rosen, M. A., Smith-Jentsch, K. A., Salas, E., Letsky, M., \& Warner, N. (2010). Toward an understanding of macrocognition in teams: Predicting processes in complex collaborative contexts. Human Factors: The Journal of the Human Factors and Ergonomics Society, 52(2), 203-224. https://doi.org/10.1177/0018720810369807

Fiore, S. M., \& Schooler, J. W. (2004). Process mapping and shared cognition: Teamwork and the development of shared problem models. Team Cognition: Understanding the Factors That Drive Process and Performance, 133-152.

Fiore, S. M., \& Wiltshire, T. J. (2016). Technology as Teammate: Examining the Role of External Cognition in Support of Team Cognitive Processes. Frontiers in Psychology, 7. https://doi.org/10.3389/fpsyg.2016.01531

Godemann, J. (2008). Knowledge integration: A key challenge for transdisciplinary cooperation. Environmental Education Research, 14(6), 625-641. https://doi.org/10.1080/13504620802469188

Goodyear, P., \& Carvalho, L. (2014). Framing the analysis of learning network architectures. The Architecture of Productive Learning Networks, 48. 
Gosselin, D., Thompson, K., Pennington, D., \& Vincent, S. (2020). Learning to be an interdisciplinary researcher: Incorporating training about dispositional and epistemological differences into graduate student environmental science teams. Journal of Environmental Studies and Sciences, 10(3), 310-326. https://doi.org/10.1007/s13412-020-00605-w

Gray, S., Mellor, D., Jordan, R., Crall, A., \& Newman, G. (2014). Modeling with citizen scientists: Using community-based modeling tools to develop citizen science projects. International Environmental Modelling and Software Society (iEMSs) 7th International Congress on Environmental Modelling and Software, San Diego, California, USA.

Hall, K. L., Vogel, A. L., Huang, G. C., Serrano, K. J., Rice, E. L., Tsakraklides, S. P., \& Fiore, S. M. (2018). The science of team science: A review of the empirical evidence and research gaps on collaboration in science. American Psychologist, 73(4), 532-548. https://doi.org/10.1037/amp0000319

Hamilton, S. H., ElSawah, S., Guillaume, J. H. A., Jakeman, A. J., \& Pierce, S. A. (2015). Integrated assessment and modelling: Overview and synthesis of salient dimensions. Environmental Modelling \& Software, 64, 215-229. https://doi.org/10.1016/j.envsoft.2014.12.005

Jakeman, A. J., Letcher, R. A., \& Norton, J. P. (2006). Ten iterative steps in development and evaluation of environmental models. Environmental Modelling \& Software, 21(5), 602-614. https://doi.org/10.1016/j.envsoft.2006.01.004

Johnson, K. A., Dana, G., Jordan, N. R., Draeger, K. J., Kapuscinski, A., Schmitt Olabisi, L. K., \& Reich, P. B. (2012). Using Participatory Scenarios to Stimulate Social Learning for Collaborative Sustainable Development. Ecology and Society, 17(2). https://doi.org/10.5751/ES-04780-170209

Killion, A. K., Sterle, K., Bondank, E. N., Drabik, J. R., Bera, A., Alian, S., Goodrich, K. A., Hale, M., Myer, R. A., Phung, Q., Shew, A. M., \& Thayer, A. W. (2018). Preparing the next generation of sustainability scientists. Ecology and Society, 23(4), 39-51. https://doi.org/10.5751/ ES-10395-230439

Klein, J. T. (2020). Sustainability and Collaboration: Crossdisciplinary and Cross-Sector Horizons. Sustainability, 12(4), 1515. https://doi.org/10.3390/su12041515

Knight, S., \& Thompson, K. (2018). Developing a text-integration task for investigating and teaching interdisciplinarity in science teams. In J. Kay \& R. Luckin (Eds.), Rethinking Learning in the Digital Age: Making the Learning Sciences Count (Vol. 3). International Society of the Learning Sciences.

Knight, S., \& Thompson, K. (2020). Developing a Text-Integration Task for Investigating and Teaching Interdisciplinarity in Science Teams. Research in Science Education. https://doi.org/10.1007/s11165-020-09937-7

Koch, J., Friedman, J. R., Paladino, S., Plassin, S., \& Spencer, K. (2019). Conceptual modeling for improved understanding of the Rio Grande/Río Bravo socio-environmental system. Socio-Environmental Systems Modelling, 1, 16127. https://doi.org/10.18174/sesmo.2019a16127

Kolb, A. Y. K. (2005). Learning styles and learning spaces: Enhancing experiential learning in higher education. Academy Of Management Learning \& Education, 4(2), 193-212.

Kolb, D. A. (1984). Experiential Learning: Experience as the Source of Learning and Development. Prentice-Hall.

Larkin, J. H., \& Simon, H. A. (1987). Why a Diagram is (Sometimes) Worth Ten Thousand Words. Cognitive Science, 11(1), 65100. https://doi.org/10.1111/j.1551-6708.1987.tb00863.

Lee, C. (2007). Boundary negotiating artifacts: Unbinding the routine of boundary objects and embracing chaos in collaborative work. Computer Supported Cooperative Work, 16, 307-339.

Marks, M. A., Mathieu, J. E., \& Zaccaro, S. J. (2001). A temporally based framework and taxonomy of team processes. Academic Management Review 26: 356-376.

Mathieu, J. E., Gallagher, P. T., Domingo, M. A., and Klock, E. A. (2019). Embracing complexity: Reviewing the past decade of team effectiveness research. Annual Review of Organizational Psychology and Organizational Behavior, 6McGrath, J. E. (1964). Social Psychology: A Brief Introduction. New York: Holt, Rinehart and Winston.

Mezirow, J. (1981). A Critical-Theory Of Adult Learning And Education. Adult Education, 32(1), 3-24. URL

Mezirow, J. (1997). Transformative learning: Theory to practice. New Directions for Adult and Continuing Education, 1997(74), 5-12. http://onlinelibrary.wiley.com/doi/10.1002/ace.7401/full

Mezirow, J. (2018). An Overview on Transformative Learning (reprint from 2006). In K. Illeris (Ed.), Contemporary Theories of Learning: Learning theorists ... in their own words (2nd Edition, p. 244). Routledge.

Misra, S., Stokols, D., \& Cheng, L. (2015). The Transdisciplinary Orientation Scale: Factor Structure and Relation to the Integrative Quality and Scope of Scientific Publications. Journal of Collaborative Healthcare and Translational Medicine, 3(2), 1042.

National Academy of Sciences. (2004). Facilitating Interdisciplinary Research (p. 332). National Academies Press. http://www.nap.edu/catalog.php?record_id=11153

National Research Council. (2015). Enhancing the Effectiveness of Team Science: Committee on the Science of Team Science (N. J. Cooke \& M. L. Hilton, Eds.). The National Academies Press.

Nersessian, N. J. (1999). Model-Based Reasoning in Conceptual Change. In L. Magnani, N. J. Nersessian, \& P. Thagard (Eds.), Model-Based Reasoning in Scientific Discovery (pp. 5-22). Springer US. http://link.springer.com/chapter/10.1007/978-1-4615-4813-3_1

Nersessian, N. J. (2006). Model-based reasoning in distributed cognitive systems. PHILOSOPHY OF SCIENCE, 73(5), 699-709. https://doi.org/10.1086/518771

Norström, A. V., Cvitanovic, C., Löf, M. F., West, S., Wyborn, C., Balvanera, P., Bednarek, A. T., Bennett, E. M., Biggs, R., Bremond, A. de, Campbell, B. M., Canadell, J. G., Carpenter, S. R., Folke, C., Fulton, E. A., Gaffney, O., Gelcich, S., Jouffray, J.-B., Leach, M., ... Österblom, H. (2020). Principles for knowledge co-production in sustainability research. Nature Sustainability, 1-9. https://doi.org/10.1038/s41893-019-0448-2 
O’Rourke, M., Crowley, S., Eigenbrode, S. D., \& Wulfhorst, J. (2013). Enhancing communication \& collaboration in interdisciplinary research. Sage Publications.

O'Rourke, M., Crowley, S., \& Gonnerman, C. (2016). On the nature of cross-disciplinary integration: A philosophical framework. Studies in History and Philosophy of Science Part C: Studies in History and Philosophy of Biological and Biomedical Sciences, 56, 62-70.

Ostrom, E. (2007). A diagnostic approach for going beyond panaceas. Proceedings of the National Academy of Sciences, 104(39), 15181-15187. https://doi.org/10.1073/pnas.0702288104

Pennington, D. D. (2008). Cross-disciplinary collaboration and learning. Ecology and Society, 13(2), 8. https://www.ecologyandsociety.org/vol13/iss2/art8/

Pennington, D. D. (2016). A conceptual model for knowledge integration in interdisciplinary teams: Orchestrating individual learning and group processes. Journal of Environmental Studies and Sciences, 6(2), 300-312. https://rdcu.be/6Cip. https://doi.org/10.1007/s13412-015-0354-5

Pennington, D. D., Bammer, G., Danielson, A., Gosselin, D., Gouvea, J., Habron, G., Hawthorne, D., Parnell, R., Thompson, K., Vincent, S., \& Wei, C. (2016). The EMBeRS project: Employing model-based reasoning in socio-environmental synthesis. Journal of Environmental Studies and Sciences, 6(2), 278-286. https://rdcu.be/6CwZ. https://doi.org/10.1007/s13412-015-0335-8

Pennington, D. D., Bondank, E., Clifton, J., Killion, A., Salas, K., Shew, A., Sterle, K., \& Wilson, B. (2018). EMBeRS: An approach for igniting participatory learning and synthesis. In M. Arabi, O. David, J. Carlson, \& D. P. Ames (Eds.), Proceedings of the 9th International Congress on Environmental Modelling and Software. International Association of Environmental Modelling and Software. https://scholarsarchive.byu.edu/iemssconference/2018/Stream-C/68/

Pennington, D. D., Simpson, G., McConnell, M., Fair, J., \& Baker, R. (2013). Transdisciplinary science, transformative learning, and transformative science. BioScience, 63(7), 564-573.

Pennington, D., Ebert-Uphoff, I., Freed, N., Martin, J., \& Pierce, S. (2020). Bridging sustainability science, earth science, and data science through interdisciplinary education. Sustainability Science. https://doi.org/doi:10.1007/s11625-01900735-3

Pennington, Deana. (2012, April 18). A Model for Knowledge Synthesis Across Disciplines [Conference Presentation]. 3rd Annual Conference for the Science of Team Science, Northwestern University, Chicago, IL. https://www.inscits.org/2012-scits-conference

Roy, E. D., Morzillo, A. T., Seijo, F., Reddy, S. M. W., Rhemtulla, J. M., Milder, J. C., Kuemmerle, T., \& Martin, and S. L. (2013). The Elusive Pursuit of Interdisciplinarity at the Human-Environment Interface. BioScience, 63(9), 745-753. https://doi.org/10.1525/bio.2013.63.9.10

Schneider, B., Dowell, N., \& Thompson, K. (2021). Collaboration Analytics-Current State and Potential Futures. Journal of Learning Analytics, 8(1), 1-12.

Schneider, F., \& Rist, S. (2014). Envisioning sustainable water futures in a transdisciplinary learning process: Combining normative, explorative, and participatory scenario approaches. Sustainability Science, 9(4), 463-481. https://doi.org/10.1007/s11625-013-0232-6

Scholz, G., Dewulf, A., \& Pahl-Wostl, C. (2014). An Analytical Framework of Social Learning Facilitated by Participatory Methods. Systemic Practice and Action Research, 27(6), 575-591. https://doi.org/10.1007/s11213-013-9310-z

Star, S., \& Griesemer, L. (1989). Institutional ecology, translations and boundary objects-Amateurs and professionals in Berkeleys Museum of Vertebrate Zoology, 1907-39. Social Studies of Science, 19(3), 387-420. URL

Stokols, D., Misra, S., Moser, R. P., Hall, K. L., \& Taylor, B. K. (2008). The ecology of team science: Understanding contextual influences on transdisciplinary collaboration. American Journal of Preventative Medicine, 35(2S), S96-S115. URL

Thompson, K., Gouvea, J., \& Habron, G. (2016). A design approach to understanding the activity of learners undertaking a model based reasoning course: Environment and diversity. International Conference of the Learning Sciences, Singapore.

Thompson, Kate, Alhada, S., Buckingham Shum, S., Howard, S. K., Knight, S., Martinez-Maldonado, R., \& Pardo, A. (2018). Connecting expert knowledge in the design of classroom learning experiences. In J. Lodge, J. Cooney Horvath, \& L. Corrin (Eds.), Learning analytics in the classroom: Translating research for teachers. Routledge.

Thompson, Kate, Danielson, A., Gosselin, D., Knight, S., Martinez-Maldonado, R., Parnell, R., \& Pennington, D. (2017). Designing the EMBeRS Summer School: Connecting Stakeholders in Learning, Teaching and Research. Proceedings of the 25th International Conference on Computers in Education, 6.

Thompson, Kate, Wheeler, P., \& Vasco, D. (2020). Identifying connectedness in individual and group artefacts during a graduate Summer School in interdisciplinary research. Interdisciplinary learning in undergraduate and graduate education: Conceptualisations and empirical accounts symposium, International Conference of the Learning Sciences, Nashville, TN.

Villamor, G. B., Griffith, D. L., Kliskey, A., \& Alessa, L. (2020). Contrasting stakeholder and scientist conceptual models of foodenergy-water systems: A case study in Magic Valley, Southern Idaho. Socio-Environmental Systems Modelling, 2, 16312-16312. https://doi.org/10.18174/sesmo.2020a16312

Voinov, A., \& Bousquet, F. (2010). Modelling with stakeholders. Environmental Modelling \& Software, 25(11), $1268-1281$. https://doi.org/16/j.envsoft.2010.03.007

Voinov, A., Kolagani, N., McCall, M. K., Glynn, P. D., Kragt, M. E., Ostermann, F. O., Pierce, S. A., \& Ramu, P. (2016). Modelling with stakeholders - Next generation. Environmental Modelling \& Software, 77, 196-220. https://doi.org/10.1016/j.envsoft.2015.11.016 
Yokohata, T., Tanaka, K., Nishina, K., Takahashi, K., Emori, S., Kiguchi, M., Iseri, Y., Honda, Y., Okada, M., Masaki, Y., Yamamoto, A., Shigemitsu, M., Yoshimori, M., Sueyoshi, T., Iwase, K., Hanasaki, N., Ito, A., Sakurai, G., lizumi, T., ... Oki, T. (2019). Visualizing the interconnections among climate risks. Earth's Future, 7(2): 85-100. https://doi.org/10.1029/2018EF000945

Xue, L., Bot, G. L., Petegem, W. V., \& Wieringen, A. van. (2018). Defining interdisciplinary competencies for audiological rehabilitation: Findings from a modified Delphi study. International Journal of Audiology, 57(2), 81-90. https://doi.org/10.1080/14992027.2017.1406156

Xue, L., Rienties, B., Petegem, W. V., \& Wieringen, A. van. (2020). Learning relations of knowledge transfer (KT) and knowledge integration (KI) of doctoral students during online interdisciplinary training: An exploratory study. Higher Education Research \& Development, 0(0), 1-18. https://doi.org/10.1080/07294360.2020.1712679 